\title{
BMJ Open Associated factors for progression to AIDS among HIV-infected people who use drugs: a retrospective cohort study in Dongguan, China
}

\author{
Hao Luo, ${ }^{1}$ Mingwei Sun, ${ }^{2}$ Jinlin $\mathrm{Du}^{2}$
}

To cite: Luo H, Sun M, Du J. Associated factors for progression to AIDS among HIVinfected people who use drugs: a retrospective cohort study in Dongguan, China. BMJ Open 2019;9:e023841. doi:10.1136/ bmjopen-2018-023841

- Prepublication history for this paper is available online. To view these files please visit the journal online (http://dx.doi. org/10.1136/bmjopen-2018023841).

Received 28 April 2018 Revised 11 March 2019 Accepted 23 May 2019
Check for updates

(C) Author(s) (or their employer(s)) 2019. Re-use permitted under CC BY-NC. No commercial re-use. See rights and permissions. Published by BMJ.

${ }^{1}$ Department of Environmental and Occupational Health, Dongguan Key Laboratory of Environmental Medicine, School of Public Health, Guangdong Medical University, Zhanjiang, China

${ }^{2}$ Department of Epidemiology and Health Statistics, School of Public Health, Guangdong Medical University, Dongguan, China

Correspondence to

Dr Jinlin Du;

dujinlin03@163.com

\section{ABSTRACT}

Objectives Injection drug use is the most important risk factor for the spread of HIV in China over the past two decades. People who use drugs (PWUD) who were diagnosed at an early stage with HIV have gradually developed AIDS. This study investigated the factors associated with disease progression following HIV diagnosis in PWUD.

Design This study used a retrospective cohort study. Setting This investigation was conducted in Dongguan city, Guangdong Province, China.

Participants A total of 2969 PWUD with HIV were recruited from 1 January 1995 to 31 December 2014. Primary and secondary outcome measures KaplanMeier method, Logistic regression and Cox proportional hazards regression model were applied to identify the related factors of progression to AIDS following HIV diagnosis.

Results The study revealed that age at diagnosis, marital status, baseline CD4 T-cell counts and highly active antiretroviral therapy (HAART) were statistically significant $(p<0.01)$, either in the patients with HIV or in patients with AIDS. Compared with HIV-infected individuals of 18 years, patients with AIDS who were at least 36 years of age possessed sharply increased HR for developing AIDS ( $\mathrm{HR}=7.016,95 \% \mathrm{Cl} 6.083$ to 8.092, $\mathrm{p}=0.001$ ). The single HIV-positive individuals ( $\mathrm{HR}=0.691,95 \% \mathrm{Cl} 0.588$ to 0.811 , $p=0.001$ ) were less likely to develop AIDS compared with married ones. Increasing baseline CD4 T-cell counts, HAART (HR=0.599, 95\% $\mathrm{Cl} 0.517$ to $0.693, p=0.001$ ) and condom usage ( $\mathrm{HR}=0.825,95 \% \mathrm{Cl} 0.710$ to 0.959 , $\mathrm{p}=0.012$ ) were associated with delayed progression to AIDS.

Conclusions Our study found that increasing baseline CD4 T-cell counts, HAART and condom usage might be associated with delayed the progression of HIV to AIDS, while increasing age at diagnosis, marital status increased hazard for developing AIDS

\section{INTRODUCTION}

Since the HIV infection was identified in 1985, ${ }^{1}$ HIV has spread fast in China. By the end of 2016, it was reported that there had been approximately 654000 people with HIV/ AIDS in China. Injection drug use (IDU) has

\section{Strengths and limitations of this study}

- The current study is the first to observe the factors associated with disease progression among people who use drugs in Asia.

- The study included 20-year retrospective follow-up and had involved large sample size bigger than other similar studies.

- However, this study is based on retrospective data owing to self-report measures and does not contain viral load measurements at the time of diagnosis, which may bias the results.

- In our study, we did not obtain the information on when patients actually contracted HIV, detailed information on patterns of substance use, treatment course and clinical events, which might affect our results.

been the most important risk factor for HIV spread in China over the past two decades. ${ }^{2}$ In recent years, the rate of transmission via drug injection among newly diagnosed HIV/ AIDS cases has dropped from $44.2 \%$ in 2003 to $7.7 \%$ in 2013 because the community methadone maintenance treatment on drug addiction and rehabilitation has been actively explored. Despite this, risky injection behaviour continues to cause the majority of the cumulative HIV/AIDS infections. ${ }^{34}$ At the end of 2013, the total HIV antibody positive rate among people who use intravenous drugs was $6.3 \%$ nationwide. ${ }^{5}$

Guangdong lies on a major heroin trade route from the Myanmar border through Yunnan and Guangxi towards the north of China, and its HIV epidemic has been primarily driven by IDU. ${ }^{6}$ Now, HIV-infected individuals who have been diagnosed early have gradually developed AIDS. In China, the National Free Antiretroviral Treatment Program (NFATP) was initiated in 2002 and subsequently expanded nationwide in 2003. ${ }^{78}$ It was the further scale-up HIV testing among key populations and immediate initiation of 
antiretroviral therapy (ART) from 2008 onwards. ${ }^{9}$ At the end of 2014, more than 363000 patients in China had received ART. ${ }^{10}$ Although highly active antiretroviral therapy (HAART) has slowed down the progression of HIV from the time of diagnosis to AIDS, ${ }^{11-13}$ the progression is still affected by other risk factors. Several studies have suggested that age at diagnosis and transmission categories influence the onset of AIDS. ${ }^{14} 15$ The CD4 T-cell status has been recognised as a surrogate marker for HIV infection and the most important prognostic indicator of disease progression among individuals infection with HIV. ${ }^{16}$ We questioned if the factors associated with the progression to AIDS among HIV-positive individuals of people who use drugs (PWUD) in Guangdong is similar to those reported in previous studies. To attain a better understanding of HIV progression among PWUD in Guangdong, we used data from the Center for Disease Control and Prevention (CDC), Dongguan, through the national surveillance system to measure the associated factors for progression to AIDS.

\section{METHODS}

\section{Study design and subjects}

A retrospective study was implemented using data obtained through two national databases. The first was an epidemiological database of the national surveillance system. Basic demographic information, date of diagnosis, sexual behaviours and clinical information including the baseline CD4 T-cell counts were obtained from this system. The second database was the national treatment database, including all patients who met the national treatment criteria and were provided free treatment. $^{71819}$ The national treatment criteria referred to WHO stage III or IV disease, CD4 T-cell count $<200$ cells/ $\mu \mathrm{L}$ (increasing to $<350$ cells $/ \mu \mathrm{L}$ in 2008 ) or total lymphocyte count $<1200 / \mathrm{mm}^{3}$. HIV-infected individuals and patients with AIDS were seen in follow-up every 6 months and 3 months. After each visit, local healthcare providers completed a standardised case report form (CRF) and faxed the form to the China CDC via Datafax. ${ }^{19}$ These CRFs were then maintained in an ongoing observational treatment database. ${ }^{18}$

The cohort started in 1 January 1995 among PWUD. The inclusion criteria for participation include subjects who (1) resided in Dongguan for at least 3 years, (2) were older than 18 years of age at the time of HIV-positive diagnosis by Western blot tests and (3) history of drug use. A PWUD was defined as an individual who had used any illicit drug through mouth or injections, at least once in the past 3 months before the interview. A case of AIDS was defined as a presumptive or definitive diagnosis of stage 4 conditions and/or CD4 T-cell count less than $200 / \mathrm{mm}^{3}$ of blood in HIV-infected subject. ${ }^{20}$ We excluded HIV-positive individuals who defaulted the follow-up phase, subjects without baseline CD4 T-cell counts or those who died from causes other than AIDS. The subjects were followed up from the date of confirmed HIV diagnosis until 31
December 2014. It was presumed that the disease did not progress to AIDS for subjects who were free of AIDS diagnosis report at censoring. Of the 3042 HIV-infected PWUD who met the criteria, $73(2.40 \%)$ were excluded from the analyses because of defaulted follow-up and because they died from other causes (figure 1).

\section{Patient and public involvement}

Patients were not involved in the design and conduct of the study.

\section{Statistical analysis}

The information on diagnosis of HIV infection was estimated using the date of positive Western blot test. The observation period ended on 31 December 2014, or at the last follow-up visit, or until progression to AIDS.

The proportion of HIV-infected individuals who were developing AIDS were estimated at 2 and 5 years according to Kaplan-Meier analysis with Greenwood SE. Stratified analyses were conducted by gender, age at HIV diagnosis, marital status, baseline CD4 T-cell counts, HAART, condom usage and consulting service (defined as providing AIDS-related knowledge, promotional materials, disease prevention and treatment). Non-conditional logistic regression analysis was applied to calculate the ORs and their corresponding 95\% CIs and was used to address the potential risk factor of AIDS morbidity.

HRs and their corresponding 95\% CIs derived from the Cox proportional hazards regression models which

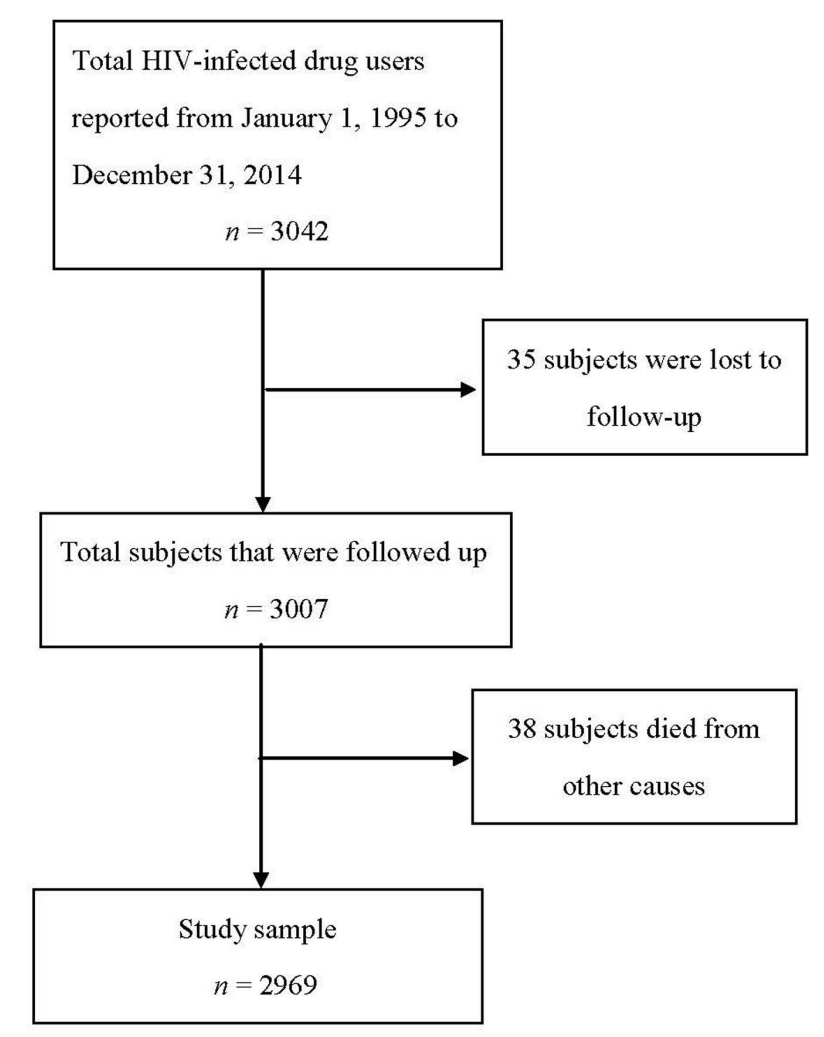

Figure 1 Flow diagram showing the selection of study subjects. 
were applied to assess the progress of HIV-infected individuals and their potential risk factors after adjusted the confounding variables. All of the confounding variables which were statistically significant in univariate analysis were selected by the enter method in non-conditional logistic regression models and Cox proportional hazards regression models. The data were analysed using SPSS for Windows V.19.0. All statistical tests were two sided, and a $p$ value of $<0.05$ was considered statistically significant.

\section{RESULTS}

\section{Demographic characteristics}

Based on the claims data from 1 January 1995 to 31 December 2014, a total of 3042 PWUD were confirmed to be infected with HIV. Of these, 73 were lost to follow-up or had died before they progressed to AIDS; these patients were excluded. A total of 2969 patients were included in the study: of these, 1151 (37.84\%) progressed to AIDS and 1818 (59.76\%) HIV-positive individuals did not develop AIDS and were still alive. The majority of patients were male $(88.65 \%)$, and the median age at HIV diagnosis was 33 years (range, 18-66). Furthermore, 687 (23.14\%) of the patients were married and over half $(50.48 \%)$ were receiving HAART. Only 34 $(1.15 \%)$ of subjects were the methadone maintenance participants.

Table 1 shows the proportion of progression to AIDS after HIV diagnosis. The mean follow-up time was $38.53 \pm 29.12$ months. In terms of the proportion of HIV-positive individuals who developed AIDS, 3.60\%, $13.00 \%$ and $42.20 \%$ developed AIDS after 1, 2 and 5 years, respectively. An average time to progression to AIDS was $69.22 \pm 1.02$ months (95\% CI 67.975 to 74.025 ). The proportion of HIV-positive individuals with progression to AIDS demonstrated significant differences in gender, age at diagnosis, marital status, baseline CD4 cell counts, HAART, condom usage and consulting service. The rate of HIV-positive individuals with progression to AIDS increased at 5 years.

Table 1 Rate of HIV-infected PWUD and who progressed to AIDS, Kaplan-Meier analysis results according to demographic factors and selected variables at HIV diagnosis, Dongguan, China

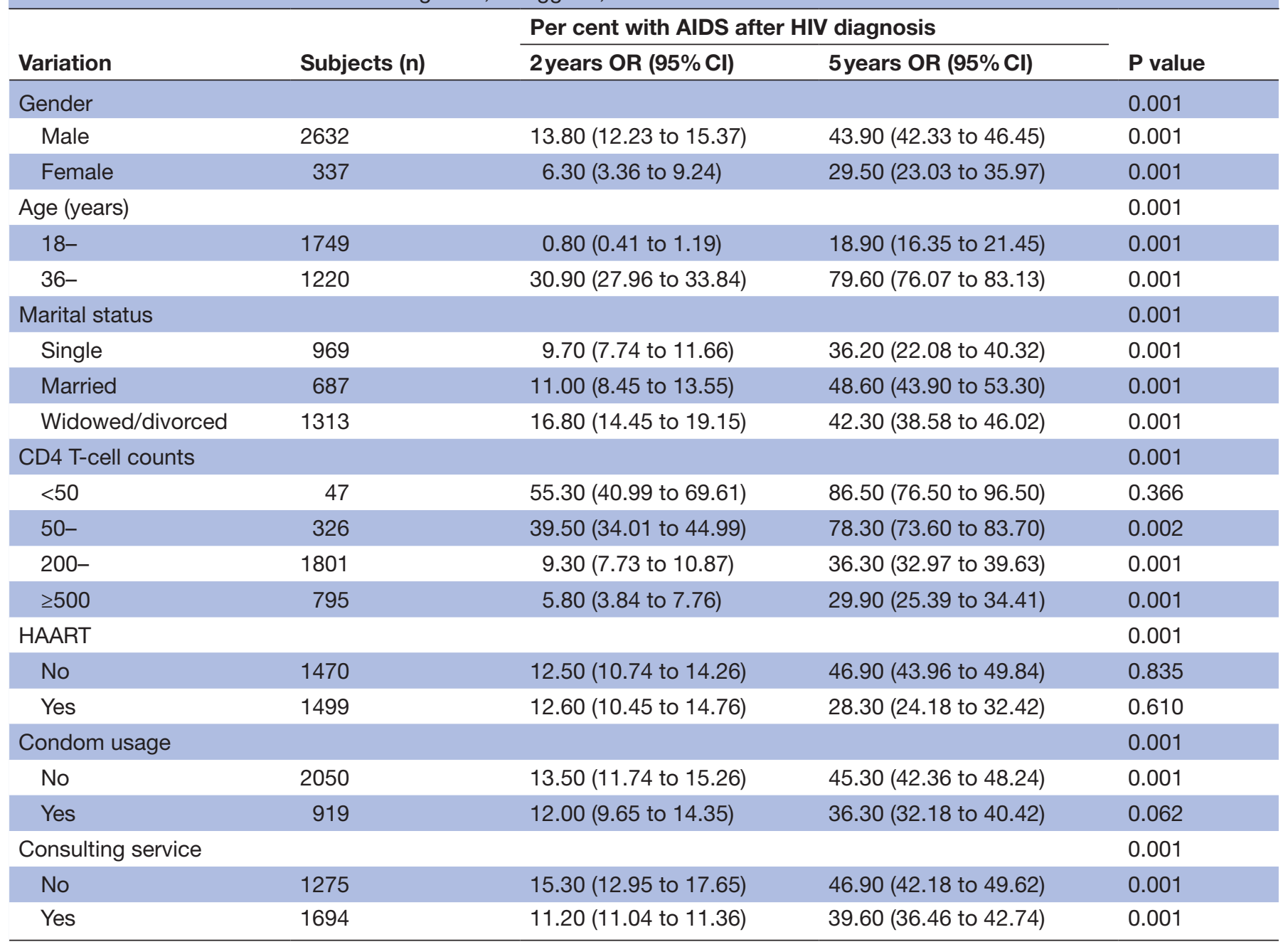

HAART, highly active antiretroviral therapy; PWUD, people who use drugs. 
In the univariate and multivariate non-conditional logistic regression analyses, the differences in the age at diagnosis, marital statuses, baseline CD4 T-cell counts and HAART between patients with HIV and AIDS were significantly different $(\mathrm{p}<0.01)$. Otherwise, HIV-positive individuals of older age ( $\geq 36$ years) at diagnosis were more likely to develop AIDS ( $\mathrm{OR}=2.711$ for 36 years vs 18 years, 95\% CI 2.200 to 3.340, $\mathrm{p}=0.001$ ). Single or widowed/divorced people, those with higher CD4 T-cell counts and those receiving HAART were less likely to develop AIDS ( $\mathrm{OR}=0.549$ for widowed/ divorced vs married, $95 \%$ CI 0.429 to $0.704, \mathrm{p}=0.001$; $\mathrm{OR}=0.532$ for single vs married, $95 \%$ CI 0.404 to 0.699 , $\mathrm{p}=0.001 ; \mathrm{OR}=0.004$ for 200 vs $<50,95 \%$ CI 0.001 to $0.028, \mathrm{p}=0.001$; OR $=0.004$ for $\geq 500$ vs $<50,95 \%$ CI 0.001 to $0.031, \mathrm{p}=0.001$; OR=0.059 for HAART vs no HAART, $95 \%$ CI 0.047 to $0.075, \mathrm{p}=0.001$; table 2 ).

Factors associated with progression to AIDS

Results of the univariate and multivariate Cox regression analysis of the factors associated with AIDS progression are presented in table 3. Univariate analysis demonstrated that gender, age at diagnosis, marital status, baseline CD4 T-cell counts, HAART, condom usage and consulting service were significantly different between HIV-infected PWUD without progression and those that showed progression to AIDS. Age and marital status might be risk factors for developing AIDS ( $<<0.005$ for all), while others turned out to be protective factors ( $\mathrm{p}<0.005$ for all). After adjustment for these factors, gender and consulting service were no longer statistically significant factors influencing AIDS progression. Otherwise, the patients aged $\geq 36$ years had a 6.083-fold higher risk of developing AIDS (HR=7.016, 95\% CI 6.083 to $8.092, \mathrm{p}=0.001$ ) compared with patients aged 18 years. Single HIV-positive individuals (HR $=0.691$, $95 \%$ CI 0.588 to $0.811, \mathrm{p}=0.001$ ) was less likely to develop AIDS compared with married people. The factors, including increasing baseline CD4 T-cell counts, HAART (HR $=0.599,95 \%$ CI 0.517 to $0.693, \mathrm{p}=0.001)$ and condom usage $(\mathrm{HR}=0.825,95 \% \mathrm{CI} 0.710$ to $0.959, \mathrm{p}=0.012)$ might reduce the risk of progression to AIDS.

\begin{tabular}{|c|c|c|c|c|}
\hline Variation & OR $(95 \% \mathrm{Cl})$ & $P$ value & Adjust OR $(95 \% \mathrm{Cl})$ * & $P$ value \\
\hline Gender & & 0.503 & & 0.661 \\
\hline Male & 1.00 & & 1.00 & \\
\hline Female & $0.92(0.73$ to 1.17$)$ & & 1.07 (0.79 to 1.46$)$ & \\
\hline Age (years) & & 0.001 & & 0.001 \\
\hline $18-$ & 1.00 & & 1.00 & \\
\hline $36-$ & 2.43 (2.09 to 2.83 ) & & 2.71 (2.20 to 3.34$)$ & \\
\hline Marital status & & 0.001 & & 0.001 \\
\hline Married & 1.00 & & 1.00 & \\
\hline Widowed/divorced & 0.60 (0.50 to 0.73$)$ & 0.001 & 0.55 (0.43 to 0.70$)$ & 0.001 \\
\hline Single & 0.52 (0.43 to 0.64$)$ & 0.001 & $0.53(0.40$ to 0.70$)$ & 0.001 \\
\hline CD4 T-cell counts & & 0.001 & & 0.001 \\
\hline$<50$ & 1.00 & & 1.00 & \\
\hline $50-$ & 0.33 (0.04 to 2.54$)$ & 0.288 & 0.24 (0.034 to 1.864$)$ & 0.171 \\
\hline $200-$ & 0.01 (0.00 to 0.07$)$ & 0.001 & 0.00 (0.00 to 0.03$)$ & 0.001 \\
\hline$\geq 500$ & 0.01 (0.00 to 0.07 ) & 0.001 & 0.00 (0.00 to 0.03$)$ & 0.001 \\
\hline HAART & & 0.001 & & 0.001 \\
\hline No & 1.00 & & 1.00 & \\
\hline Yes & 0.12 (0.10 to 0.14$)$ & & 0.06 (0.05 to 0.08$)$ & \\
\hline Condom usage & & 0.149 & & 0.642 \\
\hline No & 1.00 & & 1.00 & \\
\hline Yes & 1.12 (0.96 to 1.32$)$ & & 1.06 (0.83 to 1.36$)$ & \\
\hline Consulting service & & 0.507 & & \\
\hline No & 1.00 & & & \\
\hline Yes & 0.95 (0.82 to 1.10$)$ & & & \\
\hline
\end{tabular}

${ }^{*}$ Adjusted for factors statistically significant in univariate analysis.

HAART, highly active antiretroviral therapy; PWUD, people who use drugs. 


\section{DISCUSSION}

Assessing the characteristics and relative factors after HIV diagnosis can offer valuable information for determining the progression of HIV infection. ${ }^{14}$ Understanding the natural progression of HIV infection is important in clinical management, counselling prevention and treatment strategies. ${ }^{21}$ Our study is the first to describe the progression to AIDS after HIV diagnosis in a cohort of PWUD in Asia from 1995 to 2014. The result found that age at diagnosis, marital status, baseline CD4 cell counts, HAART and condom usage may be the factors influencing progression to AIDS. From the surveillance data, 42.20\% of HIV-infected patients progressed to AIDS after 5 years. The percentages of progression to AIDS after 1, 2 and 5 years in this study were lower than those reported in a study conducted in Wuhan and Italy. ${ }^{14} 22$ The different percentages of progression might be attributed to the economic disparity, different study population and the community methadone maintenance treatment for drug addiction and rehabilitation. Several studies support our findings that PWUD presented less likely to progress to AIDS following HIV diagnosis compared with other populations, which might be related to the younger age of PWUD. ${ }^{1423}$ In our study, we also found that the average time to progression to AIDS among HIV-infected PWUD was lower than population level, while it was higher than among HIV-infected IDUs in USA. ${ }^{24}{ }^{25}$ Disparities between risk groups in the receipt of, or the adherence to, treatment might explain the observed differences. ${ }^{25}$ Previous studies have documented that because of their exposure to disadvantaged social situation, financial difficulties and lack of family and social support, ${ }^{26-28}$ PWUD are lower in the prescription of, and the adherence to, HAART than among persons who do not use drug. ${ }^{29-31}$

This study indicated that increased age is associated with increased rate of disease progression, ${ }^{14}{ }^{15}$ which might be due to the reduced immune function and recovery and higher comorbidity. ${ }^{32-35}$ Furthermore, increased age might an increased length of time since contracting HIV. Several studies suggested that older patient had lower CD4 T-count or viral load, which might have a greater risk for progression to AIDS compared with younger ones. ${ }^{36}{ }^{37}$ Reports of gender differences in disease progression have been mixed, with some studies

Table 3 HRs and 95\% Cls of progressing to AIDS among HIV-infected individuals who use drugs, Cox proportional hazard model results according to demographic factors and selected variables at HIV diagnosis, Dongguan, China

\begin{tabular}{|c|c|c|c|c|}
\hline Variation & HR (95\% Cl) & $P$ value & Adjust HR $(95 \% \mathrm{Cl})$ * & $P$ value \\
\hline Gender & & 0.001 & & 0.108 \\
\hline Male & 1.00 & & 1.00 & \\
\hline Female & 0.61 (0.51 to 0.74$)$ & & 0.85 (0.70 to 1.04$)$ & \\
\hline Age (years) & & 0.001 & & 0.001 \\
\hline $18-$ & 1.00 & & 1.00 & \\
\hline $36-$ & 7.00 (6.11 to 8.01$)$ & & 7.02 (6.08 to 8.09$)$ & \\
\hline Marital status & & 0.001 & & 0.001 \\
\hline Married & 1.00 & & 1.00 & \\
\hline Widowed/divorced & 0.98 (0.85 to 1.12$)$ & 0.724 & 1.01 (0.87 to 1.16$)$ & 0.944 \\
\hline Single & 0.77 (0.66 to 0.90$)$ & 0.001 & 0.69 (0.59 to 0.81$)$ & 0.001 \\
\hline CD4 T-cell counts & & 0.001 & & 0.001 \\
\hline$<50$ & 1.00 & & 1.00 & \\
\hline $50-$ & 0.54 (0.40 to 0.74$)$ & 0.001 & 0.51 (0.37 to 0.70$)$ & 0.001 \\
\hline $200-$ & $0.18(0.13$ to 0.24$)$ & 0.001 & $0.16(0.12$ to 0.22$)$ & 0.001 \\
\hline$\geq 500$ & 0.14 (0.11 to 0.20$)$ & 0.001 & $0.17(0.12$ to 0.23$)$ & 0.001 \\
\hline HAART & & 0.001 & & 0.001 \\
\hline No & 1.00 & & 1.00 & \\
\hline Yes & 0.59 (0.51 to 0.68$)$ & & 0.60 (0.52 to 0.69$)$ & \\
\hline Condom usage & & 0.001 & & 0.012 \\
\hline No & 1.00 & & 1.00 & \\
\hline Yes & 0.79 (0.70 to 0.89$)$ & & 0.83 (0.71 to 0.96$)$ & \\
\hline Consulting service & & 0.001 & & 0.238 \\
\hline No & 1.00 & & 1.00 & \\
\hline Yes & 0.82 (0.73 to 0.92$)$ & & 0.92 (0.81 to 1.06$)$ & \\
\hline
\end{tabular}

${ }^{*}$ Adjusted for factors statistically significant in univariate analysis. 
reporting higher male mortality, ${ }^{34}$ female mortality ${ }^{38}$ or no difference. ${ }^{35} 3940$ In this study, we found that gender did not influence the progression of HIV to AIDS. Marital status is still an important factor affecting progression to AIDS. We observed that people who are single had lower risk of progression to AIDS compared with married people, which was inconsistent with the previous study. ${ }^{41}$ Although it is not known why married people increase the likelihood of progression to AIDS, we speculate that it may be related to where singles are more likely to have contracted HIV early, which may affect his or her marital status. Meanwhile, people who are single contracted the virus earlier and who had lower risk of progression AIDS might be attributed to the younger age with better autoimmune status and earlier stage of treatment at the time of treatment. Another explanation for the much lower percentages of disease progression experienced by single may stem from that they are more likely to have contracted it recently, especially if they are sexually active with multiple.

HAART significantly improves the prognosis of HIV-infected persons by reducing the HIV viral load, increasing the CD4 T-cell levels and delaying the progression to AIDS. ${ }^{11}$ Therefore, the level of CD4 as a clinical indicator for disease progression may be more meaningful. In China, the CD4 T-cell status decides whether HIV-infected individuals begin to acquire free active ART. The CD4 count criterion for treating adult patients was $<200$ cells $/ \mu \mathrm{L}$ in the first edition of the China Free ART Manual and increased to $<350$ cells $/ \mu \mathrm{L}$ in the revised version. ${ }^{74}$ Unfortunately, a substantial proportion of PWUD received a concurrent diagnosis of HIV and AIDS, and they had low CD4 T-counts at HIV diagnosis in the early study. ${ }^{25}$ In our current study, the results of non-conditional logistic regression and Cox regression analyses showed that patients with lower CD4 cell counts and those receiving HAART showed faster recovery than other patients, which is consistent with the findings of previous studies. ${ }^{141543}$

In addition to biomedical HIV prevention strategies such as circumcision and ART, condoms remain an important component of HIV prevention programmes. A previous study has demonstrated that increased condom use contributed to decline in the prevalence of HIV. ${ }^{44}$ In our study, we found that condom usage is associated with decreased risk of progression to AIDS. This result might be because condom usage can reduce the incidence of sexually transmitted diseases and pregnancy, which in turn slows down disease progression among HIV-infected PWUD.

This study has some limitations as it is based on retrospective data. First, the data did not provide information on when patients actually contracted HIV, the viral load at the time of diagnosis and the detailed data of substance use, which might affect the results. Second, we only used data from cases in Dongguan, which may be a potential cause of bias, and it was not known whether the results can be extrapolated to the other province. Third, these data are only available by self-reporting in their interview, thus there may be a potential bias due to the self-report methods. Finally, we did not obtain the changing nature of HIV treatment over time (both in terms of available medications as well as the evolving treatment programme in our area), which might affect our results.

\section{CONCLUSION}

In conclusion, this study found that progression to AIDS following HIV diagnosis differed depending on the age at diagnosis, marital status, baseline CD4 cell counts, HAART and condom usage. Also, disease progression among PWUD was shorter than among other HIV risk groups. Therefore, public health and medical services need to be improved to better target these risk factors to slow down disease progression.

Acknowledgements We thank all the participants, investigators and staff involved in this retrospective HIV cohort study.

Contributors HL is the main author and performed the statistical analyses. JD conceived the study and its design and assisted with statistical analyses. MS contributed to the revision of the article for important intellectual content.

Funding This study was supported by the Guangdong Provincial Science and Technology Program (2014A020212458).

Competing interests None declared.

Patient consent for publication Not required.

Ethics approval This study was approved by the Medical Ethics Committee of Guangdong Medical University.

Provenance and peer review Not commissioned; externally peer reviewed.

Data sharing statement No additional data available.

Open access This is an open access article distributed in accordance with the Creative Commons Attribution Non Commercial (CC BY-NC 4.0) license, which permits others to distribute, remix, adapt, build upon this work non-commercially, and license their derivative works on different terms, provided the original work is properly cited, appropriate credit is given, any changes made indicated, and the use is non-commercial. See: http://creativecommons.org/licenses/by-nc/4.0/.

\section{REFERENCES}

1. Settle E. AIDS in China: An annotated chronology 1985-2003. Montreal: China AIDS Survey, 2003.

2. Wu Z, Sullivan SG, Wang Y, et al. Evolution of China's response to HIV/AIDS. Lancet 2007;369:679-90.

3. Wu Z, Wang Y. Introduction: China meets new AIDS challenges. $J$ Acquir Immune Defic Syndr 2010;53(Suppl 1):S1-S3.

4. M Ih J, Ma Y, Wang N, et al. The HIV epidemic in Yunnan province, China, 1989-2007. J Acquir Immune Defic Syndr 2010;53:34-40.

5. National Health and Family Planning Commission of The People's Republic of China. China AIDS Response Progress Report. Available. 2014. http://www.unaids.org/en/dataanalysis/knowyourresponse/ countryprogressreports/2014countries/ce_CN_Narrative_Report.pdf (Accessed Jun 2014).

6. Centers for Disease Control and Prevention (CDC). HIV Infection-Guangdong Province, China, 1997-2007. MMWR Morb Mortal Wkly Rep 2009;58:396-400.

7. Ma Y, Zhang F, Zhao Y, et al. Cohort profile: the Chinese national free antiretroviral treatment cohort. Int J Epidemiol 2010;39:973-9.

8. Zuo Z, Liang S, Sun X, et al. Drug Resistance and Virological Failure among HIV-Infected Patients after a Decade of Antiretroviral Treatment Expansion in Eight Provinces of China. PLoS One 2016;11:e0166661

9. Zhao DC, Wen $\mathrm{Y}, \mathrm{Ma} \mathrm{Y}$, et al. Expansion of China's free antiretroviral treatment program. Chin Med J 2012;125:3514-21.

10. NCAIDS, NCSTD, and China CDC. Update on the AIDS/STD epidemic in China and main response in control and prevention in December, 2014. Chin J AIDS STD 2015;21:87. 
11. Egger M, May M, Chêne G, et al. Prognosis of HIV-1-infected patients starting highly active antiretroviral therapy: a collaborative analysis of prospective studies. Lancet 2002;360:119-29.

12. Wong $\mathrm{KH}$, Chan KC, Lee SS. Delayed progression to death and to AIDS in a Hong Kong cohort of patients with advanced HIV type 1 disease during the era of highly active antiretroviral therapy. Clin Infect Dis 2004;39:853-60.

13. Ewings FM, Bhaskaran $\mathrm{K}$, McLean $\mathrm{K}$, et al. Survival following HIV infection of a cohort followed up from seroconversion in the UK. AIDS 2008;22:89-95.

14. Jiang $\mathrm{H}$, Xie N, Cao B, et al. Determinants of progression to AIDS and death following HIV diagnosis: a retrospective cohort study in Wuhan, China. PLoS One 2013;8:e83078.

15. Chow KY, Ang LW, Verghesse I, et al. Measurable predictive factors for progression to AIDS among HIV-infected patients in Singapore. Ann Acad Med Singapore 2005;34:84-9.

16. Sterne JA, May M, Costagliola D, et al. Timing of initiation of antiretroviral therapy in AIDS-free HIV-1-infected patients: a collaborative analysis of 18 HIV cohort studies. Lancet 2009;373:1352-63.

17. Kitahata MM, Gange SJ, Abraham AG, et al. Effect of early versus deferred antiretroviral therapy for HIV on survival. N Engl J Med 2009;360:1815-26.

18. Zhang FJ, Pan J, Yu L, et al. Current progress of China's free ART program. Cell Res 2005;15(11-12):877-82.

19. Zhang F, Haberer JE, Wang Y, et al. The Chinese free antiretroviral treatment program: challenges and responses. AIDS 2007;21(Suppl 8):S143-S148

20. WHO. WHO case definitions of HIV for surveillance and revised clinical staging and immunological classification of HIV-related disease in adults and children. Geneva: Author, 2007.

21. Biggar RJ. AIDS incubation in 1891 HIV seroconverters from different exposure groups. International Registry of Seroconverters. AIDS 1990:4:1059-66.

22. Serraino D, Zucchetto A, Suligoi $B$, et al. Survival after AIDS diagnosis in Italy, 1999-2006: a population-based study. J Acquir Immune Defic Syndr 2009;52:99-105.

23. Pehrson P, Lindbäck S, Lidman C, et al. Longer survival after HIV infection for injecting drug users than for homosexual men: implications for immunology. AIDS 1997;11:1007-12.

24. Ross JM, Ying R, Celum CL, et al. Modeling HIV disease progression and transmission at population-level: The potential impact of modifying disease progression in HIV treatment programs. Epidemics 2018;23:34-41.

25. Grigoryan A, Hall HI, Durant T, et al. Late HIV diagnosis and determinants of progression to AIDS or death after HIV diagnosis among injection drug users, 33 US States, 1996-2004. PLoS One 2009; 4 :e4445.

26. Porter K, Babiker A, Bhaskaran K, et al. Determinants of survival following HIV-1 seroconversion after the introduction of HAART. Lancet 2003;362:1267-74.

27. Muga R, Egea JM, Sanvisens A, et al. Impact of injecting drug use on the interruption of antiretroviral therapies. J Epidemiol Community Health 2004;58:286-7.
28. Kleeberger CA, Buechner J, Palella F, et al. Changes in adherence to highly active antiretroviral therapy medications in the Multicenter AIDS Cohort Study. AIDS 2004;18:683-8.

29. Wood E, Montaner JS, Yip B, et al. Adherence and plasma HIV RNA responses to highly active antiretroviral therapy among HIV-1 infected injection drug users. CMAJ 2003;169:656-61.

30. Andersen R, Bozzette S, Shapiro M, et al. Access of vulnerable groups to antiretroviral therapy among persons in care for HIV disease in the United States. HCSUS Consortium. HIV Cost and Services Utilization Study. Health Serv Res 2000;35:389-416.

31. Mocroft A, Madge S, Johnson AM, et al. A comparison of exposure groups in the EuroSIDA study: starting highly active antiretroviral therapy (HAART), response to HAART, and survival. J Acquir Immune Defic Syndr 1999;22:369-78.

32. Simbulan-Rosenthal CM, Rosenthal DS, lyer S, et al. Transient poly(ADP-ribosyl)ation of nuclear proteins and role of poly(ADPribose) polymerase in the early stages of apoptosis. $J$ Biol Chem 1998;273:13703-12.

33. Manfredi R. HIV disease and advanced age: an increasing therapeutic challenge. Drugs Aging 2002;19:647-69.

34. Nyirenda M, Hosegood V, Bärnighausen T, et al. Mortality levels and trends by HIV serostatus in rural South Africa. AIDS 2007;21(Suppl 6):S73-S79.

35. Zaba B, Marston M, Crampin AC, et al. Age-specific mortality patterns in HIV-infected individuals: a comparative analysis of African community study data. AIDS 2007;21(Suppl 6):S87-S96.

36. Phillips AN, Lee CA, Elford J, et al. More rapid progression to AIDS in older HIV-infected people: the role of CD4+ T-cell counts. J Acquir Immune Defic Syndr 1991;4:970-5.

37. Phillips A, Pezzotti P. CASCADE Collaboration. Short-term risk of AIDS according to current CD4 cell count and viral load in antiretroviral drug-naive individuals and those treated in the monotherapy era. AIDS 2004;18:51-8.

38. Li X, Stanton B, Fang X, et al. Social stigma and mental health among rural-to-urban migrants in China: A conceptual framework and future research needs. World Health Popul 2006;8:14-31.

39. Furukawa A, Tada-Oikawa S, Kawanishi S, et al. $\mathrm{H} 2 \mathrm{O} 2$ accelerates cellular senescence by accumulation of acetylated p53 via decrease in the function of SIRT1 by NAD+ depletion. Cell Physiol Biochem 2007;20(1-4):45-54.

40. Lutalo T, Gray RH, Wawer M, et al. Survival of HIV-infected treatment-naive individuals with documented dates of seroconversion in Rakai, Uganda. AIDS 2007;21(Suppl 6):S15-S19.

41. Kposowa AJ. Marital status and HIV/AIDS mortality: evidence from the US National Longitudinal Mortality Study. Int $J$ Infect Dis 2013;17:e868-e874.

42. Zhang FJO. China free ART manual. Beijing: Chinese Center for Disease Control and Prevention, 2005.

43. Bray S, Gedeon J, Hadi A, et al. Predictive value of CD4 cell count nadir on long-term mortality in HIV-positive patients in Uganda. Hiv Aids 2012;4:135-40.

44. Potts M, Halperin DT, Kirby D, et al. Public health. Reassessing HIV prevention. Science 2008;320:749-50. 